\title{
O PIBID COMO ESTRATÉGIA PEDAGÓGICA NA FORMAÇÃO INICIAL DOCENTE
}

\author{
PIBID AS A PEDAGOGICAL STRATEGY IN INITIAL TEACHING EDUCATION
}

EL PIBID COMO ESTRATEGIA PEDAGÓGICA EN LA FORMACIÓN INICIAL DOCENTE

\section{Desiré Luciane Dominschek Tabatha Castro Alves}

\begin{abstract}
RESUMO: Este estudo analisa os impactos do Programa Institucional de Bolsa de Iniciação à Docência (PIBID) na educação básica a nível nacional. O PIBID é uma política pública brasileira que incentiva e valoriza o aprimoramento na formação dos docentes para a educação básica. O objetivo central desse estudo é investigar a ação do programa na formação docente, bem como analisar como está sendo conduzida a formação inicial dos professores. Optou-se em descrever o PIBID e apresentar os dados de desempenho do programa entre os anos de 2007 a 2013, de forma a ilustrar os benefícios do Programa. Como fonte de pesquisa foram utilizados os estudos de Gatti, Pimenta, Saviani, Severino e Tardif. A partir da análise documental das Portarias 038/2007, 122/2009, 096/2013, do Edital 061/2013, do Decreto 7.219/2010, do Relatório de Gestão (2009-2013) e do Relatório de Gestão (2009-2014), os resultados apresentados revelam uma política pública estruturada, que valoriza e fortalece a formação docente, traz melhoria em relação à qualidade nas escolas de rede pública, integrando as universidades e escolas, propicia a formação continuada dos professores da IES e dos Supervisores da escola.
\end{abstract}

PALAVRAS-ChAVE: Pibid. Impactos. Formação docente.

ABSTRACT: This study analyzes the impact of the Institutional Program of Initial Teaching Scholarship (PIBID) on basic education at national level. The PIBID is a Brazilian public policy that encourages and values the improvement in teacher training for basic education. The main goal of this study is to investigate the program's action in teacher training, as well as to analyze how the initial teacher education is being conducted. It was decided to describe the PIBID and present the performance data of the program through the years of 2007 to 2013, in order to illustrate the benefits of the Program. As a research source, the studies of Gatti, Pimenta, Saviani, Severino and Tardif were used. Based on the documentary analysis of the guidelines 738/2007, 122/2009, 096/2013, public notice 719/2013, Decree 7.219 / 2010, Management Report (2009-2013) and Management Report (2009-2014), the results presented reveal a structured public policy that values and strengthens teacher education, improves quality in public schools, integrating universities and schools, provides the continuing education of professors from the colleges and of school supervisors.

KEYWORDS: Pibid. Impacts. Teacher education.

RESUMEN: Este estudio analiza los impactos del Programa Institucional de Beca de Iniciación a la Docencia (PIBID) en la educación básica a nivel nacional. El PIBID es una política pública brasileña que incentiva y valoriza el perfeccionamiento en la formación de los docentes para la educación básica. El objetivo central de este estudio es investigar la acción del programa en la formación docente, así como analizar cómo se está conduciendo la formación inicial de los profesores. Se optó en describir el PIBID y presentar los datos de desempeño del programa entre los años 2007 a 2013, para ilustrar los beneficios del Programa. Como fuente de

Submetido em: 20/06/2017 - Aceito em: 10/07/2017 - Publicado em: 04/09/2017.

\begin{tabular}{|l|c|c|c|c|c|} 
(C) Rev. Inter. Educ. Sup. & Campinas, SP & v.3 & n.3 & p.624-644 & set./dez. 2017 \\
\hline
\end{tabular}


investigación se utilizaron los estudios de Gatti, Pimenta, Saviani, Severino y Tardif. A partir del análisis documental de las Ordenes 038/2007, 122/2009, 096/2013, del Decreto 061/2013, del Decreto 7.219 / 2010, del Informe de Gestión (2009-2013) y del Informe de Gestión (2009-2014) , Los resultados presentados revelan una política pública estructurada, que valora y fortalece la formación docente, trae mejoría en relación a la calidad en las escuelas de red pública, integrando las universidades y escuelas, propicia la formación continuada de los profesores de la IES y de los Supervisores de la escuela.

PALABRAS CLAVE: Pibid. Impactos. Formación docente

\section{INTRODUÇÃO}

O século XXI tem discutido de forma bastante enfática, visto a trajetória histórica da educação no Brasil, a formação de professores. Essas novas discussões são motivadas pelo quadro desafiador em que se encontra a qualidade da formação inicial docente, principalmente em relação às limitações na preparação desse profissional em relação à prática.

A formação inicial docente possui lacunas que devem ser preenchidas. Uma delas é a falta de formação prática do docente, diante dessa realidade é preciso desenvolver ações que ajudem a solucionar essa situação. Diante destes debates, entra em cena o Programa Institucional de Bolsa de Iniciação à Docência (PIBID), como política pública para a formação inicial de professores. O PIBID é um programa que incentiva e valoriza o aprimoramento na formação dos docentes para a educação básica, vinculada ao $\mathrm{DEB}^{2}$.

A partir desse viés, a pesquisa traz como problematização o fato da prática ser importante na formação inicial dos professores, e investigar-se-á se o programa pode ser utilizado como estratégia pedagógica na formação inicial docente. Quando existe a participação do PIBID como programa de formação inicial, é possível perceber uma contribuição significativa em relação à prática docente.

O estágio obrigatório ofertado na graduação é importante, porém, no contexto real, não é suficiente para desenvolver habilidades e capacidades que são necessárias para exercer a função docente no ensino básico. Gatti (2010), indica que o estágio supervisionado não é suficiente, devido a carga horária, pois, não proporciona um conhecimento mais consistente se tratando das redes básicas do ensino, a maior parte dos estágios são encaminhados para observação o que dificulta construir a prática mais efetiva e sólida.

\footnotetext{
${ }^{2}$ Diretoria de Formação de Professores da Educação Básica (DEB), órgão da Coordenação de Aperfeiçoamento de Pessoal de Nível Superior - Capes.
} 
O objetivo central desse estudo é investigar a ação do programa na formação docente, bem como analisar como está sendo conduzida a formação inicial dos professores. Optou-se em descrever o Programa Institucional de Bolsas de Iniciação à Docência (PIBID) e apresentar os impactos que esse programa traz na formação inicial. Para entender um pouco mais de como se encontra a situação atual da formação docente em relação à prática. Para tal, será realizada uma pesquisa bibliográfica a fim de analisar se de fato a prática é importante na formação inicial dos professores e investigar se o PIBID pode ser utilizado como estratégia pedagógica na formação inicial docente.

A metodologia de pesquisa deste trabalho coloca-se como pesquisa bibliográfica e documental, e os autores que serviram como base foram: Gatti, Pimenta, Saviani, Severino e Tardif. Esses autores tratam de forma específica como se encontra a estrutura da formação inicial dos professores de licenciatura, relacionados à prática docente. De acordo com Severino (2007) a Pesquisa bibliográfica tem como ponto de partida os registros já utilizados anteriormente, no qual o pesquisador se fundamenta a partir das contribuições de outros autores.

Conforme apresenta Severino (2007), a pesquisa documental é feita a partir do estudo em torno dos documentos, no entanto existem vários tipos de documentos, que podem ser utilizados como fonte, como os jornais, fotos, filmes e documentos legais. Realizamos ainda uma análise documental para a verificação de quais seriam os impactos do programa na formação inicial docente, quais as condições que permeariam essa realidade. Os documentos analisados foram as Portarias 038/2007, 122/2009, 096/2013, o Edital 061/2013, o Decreto 7.219/2010, o Relatório de Gestão (2009-2013), o Relatório de Gestão (2009-2013) e análise de alguns gráficos presentes nos relatórios de gestão.

\section{HISTÓRICO DO PIBID}

O Programa Institucional de Bolsa de Iniciação à Docência (PIBID) foi implantado conforme a Portaria 38/2007, e assinado em dezembro de 2007, na vigência do Ministro da Educação Fernando Haddad, entretanto, de acordo com o Relatório de Gestão 2009-2014 (produzido pela Secretaria de Educação Básica da CAPES), a ideia de lançar o PIBID partiu da iniciativa do Professor Dr. Jorge Almeida Guimarães na sua vigência como Presidente da Capes, no qual o PIBID foi inspirado por meio de outro programa o PIBIC ${ }^{3}$ (Programa Institucional de Bolsa de Iniciação Cientifica).

\footnotetext{
${ }^{3}$ O Programa Institucional de Bolsas de Iniciação Científica (PIBIC) visa apoiar a política de Iniciação Científica desenvolvida nas Instituições de Ensino e/ou Pesquisa, por meio da concessão de bolsas de Iniciação Científica (IC) a estudantes de graduação integrados na pesquisa científica. O PIBIC foi o primeiro programa institucional criado para a Iniciação Científica. O Programa atende instituições de Ensino e/ou Pesquisa públicas \begin{tabular}{l|l|l|l|l|l} 
(C) Rev. Inter. Educ. Sup. & Campinas, SP & v.3 & n.3 & p.624-644 & set./dez. 2017
\end{tabular}
} 
De acordo com a Portaria 38/2007 (BRASIL, 2016) o programa teve como objetivo inicial atender a carência na formação docente do ensino médio, nas áreas específicas como Física, Química, Biologia e Matemática. Nos anos finais do ensino fundamental, o foco foi voltado para as áreas de ciências e matemática.

A partir da Portaria 122/2009 ficou acordado conforme o artigo $2^{\circ}$, que o programa passaria a ter como prioridade também a educação básica, entre outras licenciaturas, essa portaria contribui na difusão do programa.

Para o ensino fundamental: I. licenciatura em Pedagogia, com destaque para prática em classes de alfabetização; II. Licenciatura em Ciências; III. Licenciatura em Matemática; IV. Licenciatura em Educação Artística e Musical V. licenciaturas com denominação especial que atendam a projetos interdisciplinares ou novas formas de organização do ensino fundamental. (BRASIL, 122/2009, 2016, s/p).

Na Portaria 38/2007, é ressaltado que o programa é voltado apenas para as Instituições Federais e no artigo $2^{\circ}$ fica acordado que as Instituições Federias não terão nenhum tipo de custos em relação ao programa, no qual a responsabilidade desse custeio ficou direcionado a $\mathrm{CAPES}^{4}$. Ficou designado como responsabilidade das Instituições Federais, realizar convênios com as redes de Educação Básica dos Municípios, dos Estados e Distrito Federal.

Conforme a Portaria 38/2007, as bolsas serão disponibilizadas nas Instituições Federais mediante a aprovação do plano de trabalho da comissão própria, constituída pela Capes, Secretária da educação Superior e Ministério da Educação, por isso é necessário que a Instituição envie o projeto para ser analisado e avaliado por essa comissão própria. Abaixo, segue na tabela 1 o número de bolsas concedidas de 2007 a 2012.

e privadas. As cotas de Iniciação Científica são concedidas diretamente às Instituições por meio de Chamada Pública de propostas. A seleção dos projetos é feita pelas instituições.

4 A Coordenação de Aperfeiçoamento de Pessoal de Nível Superior (CAPES) é um órgão do Ministério da Educação (MEC), que avalia os cursos de pós-graduação stricto sensu (mestrado e doutorado) todos os estados da Federação, e atua na formação de professores da educação básica. Seus resultados obtidos por meio das avaliações servem para aperfeiçoar os instrumentos utilizados nas Universidades e sua base serve para formular políticas na área de pós-graduação, sempre visando o avanço em relação ao conhecimento e sua construção (CAPES, 2016). Seu site está disponível em: http://www.capes.gov.br/.

n.3




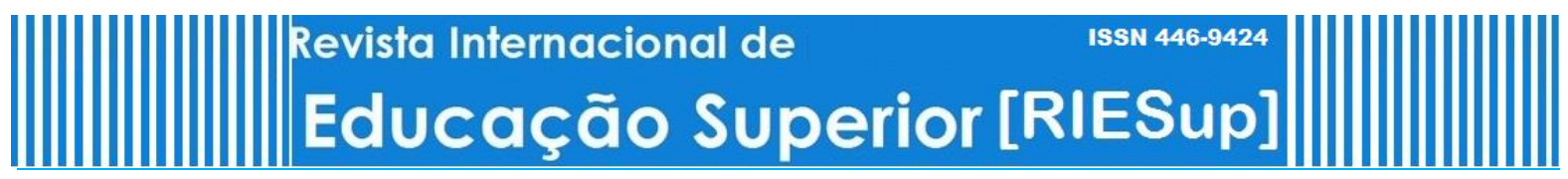

Tabela 1. Número de Bolsas Concedidas 2007-2012

\begin{tabular}{|c|c|c|c|c|c|c|c|}
\hline EDITAIS & 2007 & 2009 & 2010 & 2011 & 2012 & $\begin{array}{l}\text { Acumulado } \\
\text { com } \\
\text { Edital } 2007\end{array}$ & $\begin{array}{l}\text { Acumulado } \\
\text { sem } \\
\text { Edital } 2007\end{array}$ \\
\hline $\begin{array}{lr}\text { Bolsista } & \text { de } \\
\text { Iniciação } & \text { à } \\
\text { Docência } & \\
\end{array}$ & 2.326 & 8.882 & 2.441 & 10.526 & 18.221 & 42.396 & 40.070 \\
\hline Coordenador & 259 & 557 & 165 & 1.039 & 1.241 & 3.261 & 3.002 \\
\hline Supervisor & 503 & 1.167 & 414 & 1.727 & 2.941 & 6.752 & 6.249 \\
\hline Total & 3.088 & 10.606 & 3.020 & 13.292 & 22.403 & $52.409^{9}$ & 49.321 \\
\hline
\end{tabular}

Fonte: Capes - Relatório de Gestão 2009-2013.

Segundo o Relatório de Gestão 2009-2013, produzido pela DEB, o primeiro edital foi constituído em 2007, entretanto, o programa levou mais de dois anos para ser colocado em prática, desde então houve um grande crescimento do mesmo durante os quatro anos consecutivos (2009 a 2013). Nesse mesmo período em relação a 2009, houve a substituição das portarias pelo Decreto 7.219/2010, devido à preocupação do Ministério da Educação em relação ao fortalecimento do programa, buscou-se garantir a continuidade do programa dentro da agenda das políticas públicas educacionais.

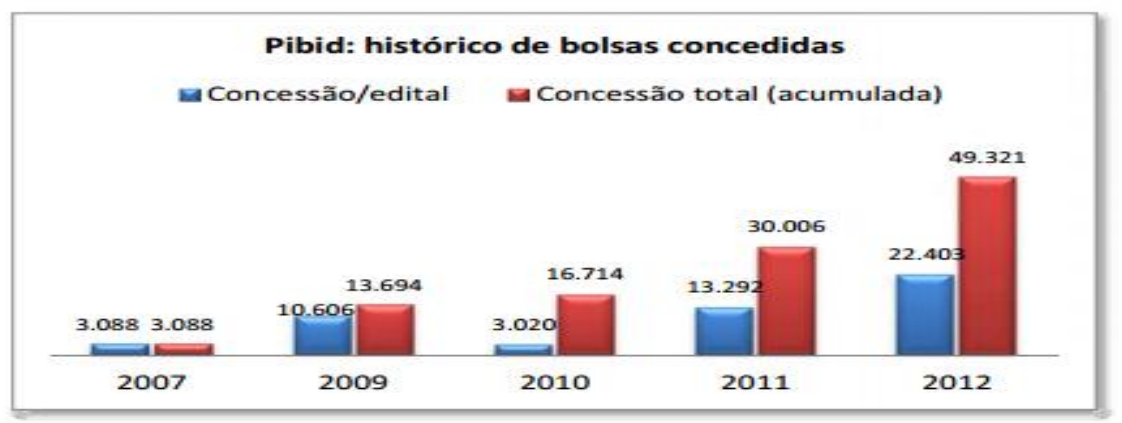

Figura 1. Número de Bolsas Concedidas 2007-2012

Fonte: Capes - Relatório de Gestão 2009-2013.

A implementação do PIBID nesse período foi de grande valia na contribuição da formação docente, porém, o fato das Universidades Privadas não terem acesso ao programa, trouxe uma certa limitação em torno da expansão do programa.

Somente a partir de 2013, quatro anos depois, o programa foi ampliado para a inserção das instituições privadas com e sem fins lucrativos, conforme o edital 061/2013, com isso houve um incentivo significativo na formação docente. O edital do Pibid 061/2013 indica que serão aceitas propostas de IES públicas e privadas, com e sem fins lucrativos, que possuam sede e administração no País; cursos de licenciatura autorizados, na forma da lei, e em funcionamento. 
O Edital 061/2013 exigiu algumas peculiaridades em relação à disponibilidade de bolsa para estudantes de Instituições Privadas, de acordo com esse edital somente os alunos que estiverem matriculados e ativos no Programa de Universidade Para Todos (PROUNI) ${ }^{5}$, podem participar do processo seletivo e ser bolsista do Programa Institucional de Bolsa de Iniciação Docente (PIBID), conforme o item 2.1.2 do edital 061/2013, as IES privadas com fins lucrativos poderão apresentar proposta, desde que os cursos de licenciatura envolvidos no projeto possuam alunos regularmente matriculados e ativos no Programa Universidade para Todos (PROUNI), em quantidade mínima para composição do subprojeto, conforme item 4.2. 2.2 A Capes verificará o atendimento aos requisitos com base nos dados cadastrados no Ministério da Educação.

A Portaria 096/2013 busca trazer de forma clara o principal objetivo do PIBID, tendo como eixo central a valorização da formação docente, contribuindo de forma significativa na elevação da qualidade da educação pública, visando à inserção dos estudantes dos cursos de licenciaturas dentro do âmbito escolar conforme o artigo $2^{\circ}$, o PIBID é um programa da Coordenação de Aperfeiçoamento de Pessoal de Nível Superior (CAPES) que tem por finalidade fomentar a iniciação à docência, contribuindo para o aperfeiçoamento da formação de docentes em nível superior e para a melhoria da qualidade da educação básica pública brasileira.

Segundo o Relatório de Gestão 2009-2013, produzido pela DEB, o PIBID é um programa que valoriza a formação inicial dos estudantes, desenvolvendo a prática docente, por meio da execução nas atividades pedagógicas, dentro da rede pública de ensino básico. Para que de fato isso aconteça é necessário que haja uma intencionalidade e direcionamento dos coordenadores e supervisores em prol de uma formação consistente para elevar o nível de conhecimento prático e teórico dos licenciados, é necessária uma interação entre ambos, tendo muito claro quais são os objetivos do PIBID.

A Portaria 096/2013, reforça que o PIBID tem como objetivo incentivar, valorizar, elevar e contribuir de forma significativa na formação inicial docente, buscando uma melhoria na qualidade da educação básica, articulando teoria e prática e ao mesmo tempo mobilizando os professores da educação básica na participação efetiva desse processo conforme o artigo $4^{\mathrm{a}}$, São objetivos do PIBID:

I - Incentivar a formação de docentes em nível superior para a educação básica;

II - Contribuir para a valorização do magistério;III - elevar a qualidade da formação inicial de professores nos cursos de licenciatura, promovendo a integração entre educação superior e educação básica; IV - Inserir os licenciados no cotidiano de escolas da rede pública de educação, proporcionando-lhes oportunidades de criação e participação em experiências metodológicas, tecnológicas e práticas docentes de caráter inovador e interdisciplinar que busquem a superação de problemas identificados no processo de ensino aprendizagem; V - Incentivar escolas públicas

\footnotetext{
5 O Programa Universidade para Todos (PROUNI) é um programa do Ministério da Educação, criado pelo Governo Federal em 2004, que concede bolsas de estudo integrais (100\%) e parciais (50\%) em instituições privadas de ensino superior, em cursos de graduação e sequenciais de formação específica, a estudantes brasileiros, sem diploma de nível superior. O site do programa está disponível em: http://siteprouni.mec.gov.br/.

\begin{tabular}{l|l|l|l|l|l} 
(C) Rev. Inter. Educ. Sup. & Campinas, SP & v.3 & n.3 & p.624-644 & set./dez. 2017 \\
\hline
\end{tabular}
}


de educação básica, mobilizando seus professores como co-formadores dos futuros docentes e tornando-as protagonistas nos processos de formação inicial para o magistério; VI - Contribuir para a articulação entre teoria e prática necessárias à formação dos docentes, elevando a qualidade das ações acadêmicas nos cursos de licenciatura; VII - contribuir para que os estudantes de licenciatura se insiram na cultura escolar do magistério, por meio da apropriação e da reflexão sobre instrumentos, saberes e peculiaridades do trabalho docente( BRASIL. 096/2013, 2016, s/p).

É papel da instituição de Ensino Superior, oferecer um ambiente que valorize o processo de aprendizagem, de acordo com a Portaria 096/2013, no qual esse trabalho é pautado na valorização da formação inicial docente, desenvolvendo ações que promovam o trabalho coletivo, visando à intencionalidade nas questões pedagógicas, por meio de vivências em diferentes espaços, de forma integradora em atividades relacionadas ao âmbito escolar, conforme o Artigo 6:

I - Estudo do contexto educacional envolvendo ações nos diferentes espaços escolares, como salas de aula, laboratórios, bibliotecas, espaços recreativos e desportivos, ateliers, secretarias;

II - Desenvolvimento de ações que valorizem o trabalho coletivo, interdisciplinar e com intencionalidade pedagógica clara para o processo de ensino-aprendizagem;

III - Planejamento e execução de atividades nos espaços formativos (escolas de educação básica e IES a eles agregando outros ambientes culturais, científicos e tecnológicos, físicos e virtuais que ampliem as oportunidades de construção de conhecimento), desenvolvidas em níveis crescentes de complexidade em direção à autonomia do aluno em formação [...] (BRASIL, 096/2013, 2016, s/p).

Ainda no artigo $6^{\circ}$ há um destaque em torno da proposta pedagógica, no qual é função da instituição criar condições e momentos que abordem debates em torno dos referenciais teóricos e da própria prática vivenciada pelos alunos, no qual é necessário promover ações que estimulem a inovação, a criatividade e a comunicação entre os pares. Essa Portaria também busca trazer a real necessidade de as Instituições incluírem nos projetos aspectos que possam expandir e aperfeiçoar a utilização da língua portuguesa, desenvolvendo a comunicação, oralidade e a escrita, como ponto central da formação docente.

VI - leitura e discussão de referenciais teóricos contemporâneos educacionais para o estudo de casos didático-pedagógicos;VII - cotejamento da análise de casos didático-pedagógicos com a prática e a experiência dos professores das escolas de educação básica, em articulação com seus saberes sobre a escola e sobre a mediação didática dos conteúdos;VIII - Desenvolvimento, testagem, execução e avaliação de estratégias didático pedagógicas e instrumentos educacionais, incluindo o uso de tecnologias educacionais e diferentes recursos didáticos; IX - Elaboração de ações no espaço escolar a partir do diálogo e da articulação dos membros do programa, e destes com a comunidade. $\mathrm{X}$ - sistematização $\mathrm{E}$ registro das atividades em portfólio ou instrumento equivalente de acompanhamento; XI - Desenvolvimento de ações que estimulem a inovação, a ética profissional, a criatividade, a inventividade e a interação dos pares [...] (BRASIL, 096/2013, 2016, s/p). 
Conforme a Portaria 096/2013 do artigo 27 as bolsas são concedidas pela CAPES, e distribuídas para o coordenador institucional, estudantes de licenciatura, para os professores de escolas públicas que supervisionam, coordenador de área e para o coordenador de área da gestão de processos educacionais. Esse edital teve como foco os aspectos pedagógicos, proporcionando um entendimento maior no que se diz respeito às contribuições e aos deveres das Instituições perante o projeto.

\section{FORMACÃO DOCENTE}

Para Tardif (2007), quando analisamos a forma como a prática está sendo inserida na grade curricular da formação inicial docente, é notório que falta a instrumentalização do que se aprendeu na teoria. Na década de 1980 não havia uma discussão sobre a prática docente, foi somente a partir da década de 1990, que houve uma preocupação maior em torno desse tema, o que trouxe melhorias significativas em relação à formação dos saberes docentes.

Durante os anos de 1989 e 1990 houve uma ênfase maior nesse assunto, devido ao fato de várias regiões do mundo estarem discutindo os embates da prática. Perceberam por meio de alguns estudos, que a realidade ensinada dentro das universidades em relação aos saberes docentes, eram distintos em relação ao cotidiano da prática escolar.

A partir desse viés Gatti (1997) aponta que não basta apenas ensinar o método e acreditar que o futuro professor estará preparado para aplicar na prática aquilo que aprendeu. Pouco se traz a instrumentalização de como o futuro professor deve ensinar. Dessa maneira os professores de nível superior deixam de lado essa prática, pois acreditam que o futuro professor vai tirar a partir dos métodos a síntese de como se deve ensinar. A maior parte das disciplinas abordadas no curso de pedagogia traz em sua especificidade as teorias pedagógicas e de como deve ser a estrutura do ensino.

Saviani (2013) traz uma reflexão em torno dessa prática, embasada por essa teoria, e ao mesmo tempo faz também a relação inversa, pois caso a prática apresente precariedade, consequentemente afetará instantaneamente a base teórica, e assim sucessivamente, por isso a importância do elo e da ligação entre ambas.

Quando entendermos que a prática será tanto mais coerente e consistente, será tanto mais qualitativa, será tanto mais desenvolvida quanto mais consistente, e desenvolvida for a teoria que a embasa, e que uma prática será transformada à medida que exista uma elaboração teórica que justifique a necessidade de sua transformação e que proponha as formas da transformação, estamos pensando a prática a partir da teoria (SAVIANI, 2013, p. 91). 
Segundo Saviani (2013) o Brasil possui grandes problemas e desafios em relação à ação pedagógica, que naturalmente precisam ser superados para se obter um resultado satisfatório no campo da educação. A falta de um sistema de educação no país, afeta diretamente o avanço da teoria, trazendo limitações em torno da prática, justamente pela forma como a estrutura organizacional está conduzida, os elementos teóricos que compõe essa estrutura inviabilizam a transformação de uma nova perspectiva teórica e prática, devido ao modelo (ingredientes teóricos) anterior estarem enraizados nessa estrutura organizacional.

Na mesma direção Gatti (2010) afirma que a grade curricular possui um perfil mais teórico, tornando-se insuficiente para atender as demandas de uma formação de qualidade. Quando a prática é contemplada dentro da grade curricular, a mesma é mais voltada à observação, sendo assim a aplicação da docência fica em segundo plano.

De acordo com Tardif (2007) a profissão do futuro professor depende de alguns saberes essenciais para exercer a sua profissão e esses saberes são necessários para aplicar em seu cotidiano. É importante que o docente domine alguns conhecimentos específicos, principalmente em relação aos conteúdos, as disciplinas e ao currículo e isso se dá por meio de vivências da prática docente.

Para que isso aconteça Libâneo (2007) destaca, que é necessário desenvolver no professor algumas capacidades, entre elas está à capacidade de refletir em torno da sua prática docente, para que seu trabalho tenha fato intencionalidade.

Para Pimenta (1994) é preciso que o docente possa ter noções básicas de como será o seu trabalho dentro da sala de aula e quais são os instrumentos necessários para exercer o seu papel, por isso a importância da práxis na formação docente como norteadora de uma formação qualificada.

De acordo com o autor Sanchez Vasquez (1977) não é possível olhar a prática de forma isolada, é necessário que exista articulação entre ambas, por meio desse conceito amplo é possível perceber que a teoria e a prática são indissociáveis.

A práxis é, na verdade, atividade teórico-prática; ou seja, tem um lado Ideal, teórico, e um lado material, propriamente prático, com a particularidade de que só parcialmente, por um processo de abstração, podemos separar, isolar um do outro (VÁSQUEZ, 1977, p.241)

Em outra obra Pimenta (2004) critica a forma como a prática é separada da teoria, isso gera grandes consequências na formação profissional a autora reforça novamente a fala de Vásquez (1977). A teoria não deve ser separada da prática, essa visão traz fragmentação no processo de formação do docente em relação a sua prática. Para Pimenta (2004), "teoria e 
prática são tratadas isoladamente, o que gera equívocos graves no processo de formação profissional. A prática pela prática e o emprego de técnicas sem a devida reflexão podem reforçar a ilusão de que há uma prática sem teoria desvinculada da prática”. ( p.39).

Conforme alinha Severino (2016) os futuros licenciados cumprem uma carga horária reduzida da prática, e dentro da grade curricular do curso a parte teórica e técnica acabam tornando-se insuficientes e precárias. Isso ocorre justamente por falta dos experimentos que a prática proporciona, tornando a formação docente limitada.

Saviani (2013) diz que não adianta culpar o professor pela sua incompetência, mas sim criticar quem realmente é responsável: o sistema educacional. É necessário conhecer e entender a forma como é estruturado, para reconhecer seus impactos na formação docente.

\begin{abstract}
Não se trata, pois, de deslocar a responsabilidade pelo fracasso escolar que atinge as crianças das camadas trabalhadoras para os professores, escamoteando o fato de que eles também são vítimas de uma situação social injusta e opressora. Isso não pode, porém, impedir-nos de constatar que sua condição de vítima se expressa também, embora não somente, pela produção de sua incompetência profissional [...] com efeito, ao criticarmos a política educacional vigente pelas distorções decorrentes de seu atrelamento aos interesses dominantes, não possível deixar de reconhecer seus efeitos sobre a formação (deformação) dos professores. (SAVIANI, 2013, p.28).
\end{abstract}

O foco da grade curricular é mais voltado às disciplinas, conteúdos e não possui uma relação voltada ao profissionalismo, dentro dessa realidade a conexão com a prática pedagógica é fragmentada. Segundo o autor Tardif (2007) o professor diante desse cenário desde sua formação não faz parte efetivamente do processo educacional, mas possui um papel mais voltado ao de um mero técnico diante do cenário educacional burocrático, pois não sabe fazer, sabe apenas aplicar, essa desvalorização se dá por meio da política, que visa somente os seus interesses, os poderes de decisão desses profissionais são reduzidíssimos.

Diante desse cenário Tardif (2007) ainda afirma que a formação docente engloba outros contextos dentro de sua prática, por isso a necessidade de uma formação mais reflexiva. Essa prática vai refletir diretamente no cotidiano escolar, por meio do currículo, da forma como vai ser ensinado e quais as metodologias que serão utilizadas por esse professor.

Ao invés de primeiro o futuro professor estudar a teoria para somente depois ter uma aproximação mínima com a prática, é necessário mudar esse caminho, para que o futuro professor possa estar diante de novos problemas e desafio e que por meio da prática possa encontrar novas soluções e esteja amparado pela fundamentação teórica (LIBÂANEO, 2007).

Portanto, o papel da teoria é oferecer aos professores perspectivas de análise para compreender os contextos históricos, sociais, culturais, organizacionais e de si 
mesmos como profissionais, nos quais se dá sua atividade docente, para neles intervir, transformando-os. Daí, é fundamental o permanente exercício da crítica às condições materiais nas quais o ensino ocorre (PIMENTA, 2004, p. 49).

O PIBID tem como concepção pedagógica uma formação pautada na colaboração de uma construção de uma nova cultura educacional, com embasamento teórico e metodológico, articulando formação docente pautada com a teoria e prática, universidade e escola, docentes e discentes, propiciando a interação entre os saberes prévios da docência, os conhecimentos teórico-práticos e saberes da pesquisa acadêmica. O PIBID busca elevar a qualidade da formação inicial de professores nos cursos de licenciatura, promovendo a integração entre educação superior e educação básica, contribuindo e articulando a teoria e prática que são necessárias na formação dos docentes, elevando a qualidade das ações acadêmicas nos cursos de licenciatura.

Contudo é importante salientar que o PIBID é diferente do estágio. O programa é uma proposta extracurricular, sua carga horária é consideravelmente maior, ao passo que o estágio faz parte do currículo do curso, com uma carga horária estabelecida pelo CNE (Conselho Nacional de Educação). Contudo essa prática dentro do espaço escolar deve ser natural e não meramente focada na observação, pois o PIBID deve propiciar vivências múltiplas em relação às questões pedagógicas, conforme indica o relatório de gestão da Capes (2009-2013).

Isso vai de acordo com o exposto pelo autor, que considera que os alunos de formação docente precisam o quanto antes, conhecer a realidade do seu trabalho dentro do espaço escolar, para que seja possível fazer a conexão com a teoria e a prática. (LIBÂNEO, 2007).

Para tanto, as atividades são organizadas de modo a valorizar a participação desses sujeitos como protagonistas de sua própria formação, tanto na escolha das estratégias e planos de ação, como, também, na definição e na busca dos referenciais teórico-metodológicos que possam dar suporte à constituição de uma rede formativa (BRASIL, 2009-2013, 2016, p.70.)

Segundo o Relatório de Gestão 2009-2013, produzido pela Secretaria de Educação Básica da CAPES, O PIBID acredita em uma ação transformadora do conhecimento da prática, defendendo a necessidade de inovar a esfera didático-pedagógica, no qual o sujeito é protagonista nesse processo por meio de sua ação. O PIBID tem como princípio transformar a percepção do sujeito que está envolvido no processo, bem como os discentes, os docentes da educação básica, e os professores da Instituição do Ensino Superior, isso se dá por meio da socialização do saber, da interação e do debate. O futuro professor precisa ser um sujeito ativo na sua formação, para a prática seja transformadora e possa ser modificada pela açãoreflexiva. 


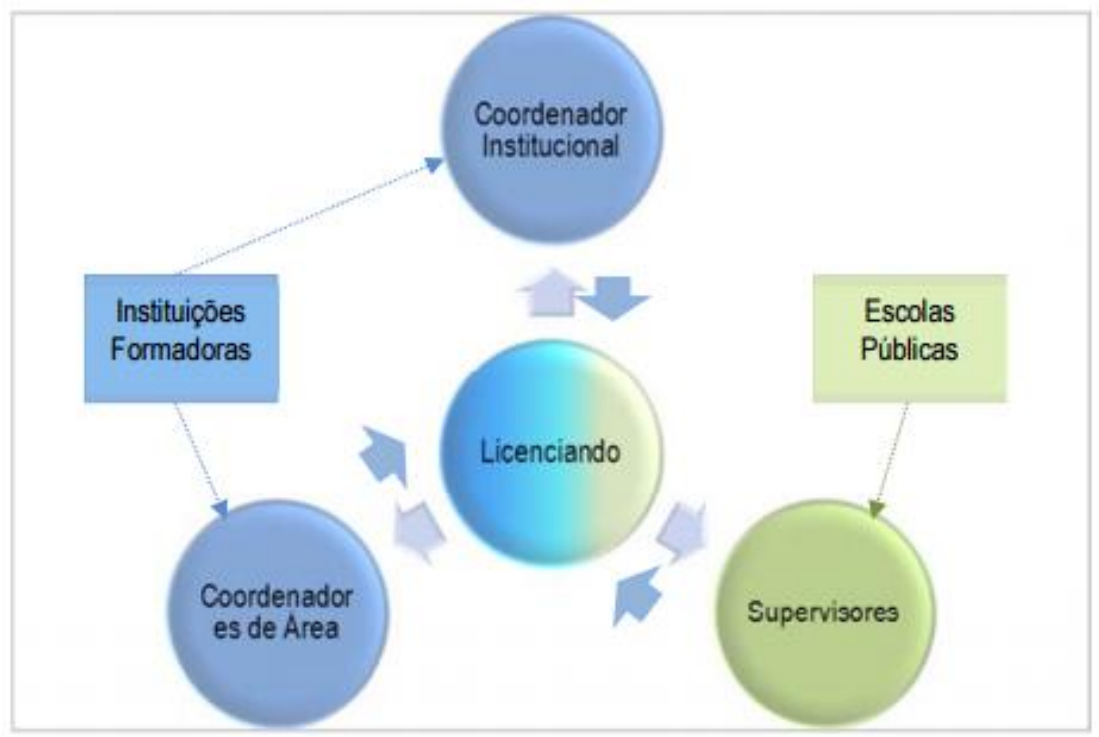

Figura 2: Desenho do Programa PIBID

Fonte: Capes - Relatório de Gestão 2013-2014.

Os estudos de Pimenta (2005) vão de encontro aos princípios do PIBID no que tange o envolvimento intencional da formação docente de forma contextualizada, por meio da práxis docente, pois o saber não se faz apenas da prática, uma vez que a mesma precisa de fundamentação teórica, para que o professor possa refletir e analisar a sua prática docente, compreendendo as mais diversas situações vivenciadas do seu cotidiano.

[...] os saberes teóricos propositivos se articulam, pois, aos saberes da prática, ao mesmo tempo ressignificando-os e sendo por eles ressignificados. O papel da teoria é oferecer aos professores perspectivas de análises para compreender os contextos históricos, sociais, culturais, organizacionais, e de si mesmos como profissionais, nos quais se dá sua atividade docente, para neles intervir, transformando-os. Daí é fundamental o permanente exercício da crítica das condições materiais nas quais o ensino ocorre. (PIMENTA, 2004, p.26)

Conforme Gatti, et al (2014), o programa traz um aprendizado mais significativo, pois os licenciados possuem um tempo de permanência maior dentro do espaço escolar, isso faz com que o bolsista tenha uma visão mais panorâmica sobre a escola, traz a consciência de todos os problemas que emergem da realidade em relação ao sistema educacional brasileiro presente, pois o licenciando não se torna um mero observador, mas participa efetivamente de sua formação docente, de forma integradora, articulando a teoria e a prática, trazendo uma ação reflexiva em torno de sua ação docente. 


\section{IMPACTOS DO PIBID NA FORMACAO DOCENTE}

O DEB acompanha o desenvolvimento do Programa nas Instituições parceiras, para que seja possível descobrir quais são os impactos do programa, isso ocorre por meio de avaliações relacionadas a visitas técnicas nas instituições, levantamento de dados em torno dos bolsistas, participação em eventos e formulários. Essas avaliações ocorrem por meio de questionário enviados pelo Google Drive, avaliação externa (relacionados com o $\operatorname{IDEB}^{6}$ ), e análises de relatório, conforme o Relatório de Gestão 2009-2013 ${ }^{7}$ (produzido pela Secretaria de Educação Básica da CAPES).

Em 2013, foram contratados consultores especialistas para realizar as avaliações externas do PIBID, foi publicado um edital com algumas exigências, no qual os selecionados deveriam fazer análises quantitativas dos formulários, produzir documento-síntese dos resultados, avaliar a estrutura do PIBID e indicar melhorias metodológicas do projeto. Foram selecionadas duas professoras: a Doutora Bernadette A. Gatti e a Doutora Marli. E. D. André, essa avaliação foi dívida entre ambas. Uma ficou responsável pela região Sul e Sudeste e a outra, Norte, Nordeste e Centro-Oeste.

GATTI et al (2014) mostram como o Programa Institucional de Bolsas de Iniciação Docente iniciou o programa com 3.088 bolsistas, contando com a participação de 43 instituições em 2009, entretanto houve um crescimento significativo nesse período no qual o PIBID chegou a alcançar 90.254 bolsistas em 284 instituições no o ano de 2013.

\footnotetext{
${ }^{6}$ O Índice de Desenvolvimento da Educação Básica (IDEB) foi criado pelo Inep em 2007 e representa a iniciativa pioneira de reunir num só indicador, dois conceitos igualmente importantes para a qualidade da educação: fluxo escolar e médias de desempenho nas avaliações. Ele agrega ao enfoque pedagógico dos resultados das avaliações em larga escala do Inep a possibilidade de resultados sintéticos, facilmente assimiláveis, e que permitem traçar metas de qualidade educacional para os sistemas. O indicador é calculado a partir dos dados sobre aprovação escolar obtidos no Censo Escolar e médias de desempenho nas avaliações do Inep, o Saeb - para as unidades da federação e para o país, e a Prova Brasil - para os municípios. (BRASIL, 2013). É elaborado pelo INEP - Instituto Nacional de Estudos e Pesquisas Educacionais, vinculado ao MEC.

${ }^{7}$ A coleta de dados foi retirada do Relatório de Gestão 2009-2013, que é um Resumo Executivo elaborado pela Diretoria de Formação de Professores da Educação Básica (DEB), órgão da Coordenação de Aperfeiçoamento de Pessoal de Nível Superior - Capes. O relatório está disponível em: https://goo.gl/vZ7k0y.
}

\begin{tabular}{l|c|c|c|c|c|} 
(C) Rev. Inter. Educ. Sup. & Campinas, SP & v.3 & n.3 & p.624-644 & set./dez. 2017
\end{tabular}


Tabela 2. Número de Bolsas Concedidas 2013

\begin{tabular}{|l|r|r|r|}
\hline \multicolumn{1}{|c|}{ Resumo } & \multicolumn{1}{c|}{ Pibid } & Pibid Diversidade & \multicolumn{1}{c|}{ Total } \\
\hline Projetos Institucionaiș & 284 & 29 & 313 \\
\hline Subprojetos & 2.916 & 81 & 2.997 \\
\hline Bolsạs & 87.060 & 3.194 & 90.254 \\
\hline Escolas & 5.398 & 657 & 6.055 \\
\hline
\end{tabular}

Fonte: Capes - Relatório de Gestão 2013-2014.

Através do gráfico mostrado na Figura 2, pode-se concluir que: o maior número de bolsas está concentrado no Nordeste e o maior percentual de concessões de bolsas está nas instituições públicas.

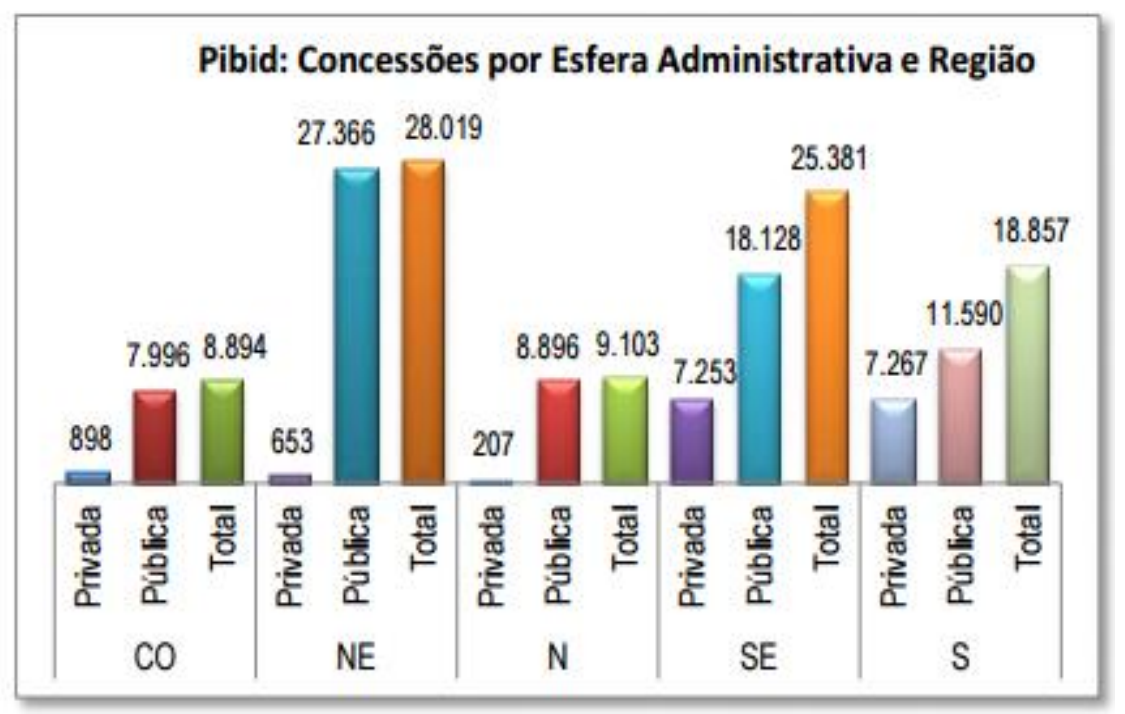

Figura 3. Número de bolsas concedidas em 2013

Fonte: Capes - Relatório de Gestão 2013-2014.

Na visão dos coordenadores institucionais houve um impacto significativo a nível nacional dentro das escolas de educação básica que participaram do programa, justamente devido ao fato do PIBID elevar a qualificação da formação dos professores e por ser uma política pública pertinente em relação à melhoria contínua dos cursos de licenciatura, que enfatiza a discussão, o debate e ações em torno da profissionalização desses futuros professores que vão atuar nas esferas da educação básica. 
Os bolsistas também tiveram a oportunidade de responder questões específicas, para que fosse possível conhecer o perfil e os anseios desses estudantes. Os bolsistas em sua grande maioria são do sexo feminino, no qual a maior parte veio de escolas públicas, os egressos do PIBID já estão atuando em escolas públicas. Esses resultados refletem positivamente na formação docente, pois esses alunos estão familiarizados com a rede púbica de ensino, o que facilita a interação nesses espaços, refletindo de forma positiva e emergente a possibilidade de uma reflexão mais ampla em torno de sua prática docente.

A participação dos bolsistas trouxe êxito e potencializaram a reabertura e melhoria na utilização dos espaços escolares, por meio das atividades mobilizadoras nesses espaços, tal como a utilização do laboratório de ciências, informática, bibliotecas, brinquedoteca, espaço esportivos e artísticos.

Conforme os relatos dos coordenadores institucionais, outro fator de impacto foi em relação ao IDEB, o programa por meio de seus resultados influenciou o aumento do índice nas escolas participantes em $40 \%$ em relação aos resultados anteriores, mesmo que esse não seja o foco do PIBID. Outra contribuição do programa que trouxe impactos relevantes nas licenciaturas foi o fato de sua principal ação estar articulada a práxis na formação docente.

Essa realidade desencadeou um envolvimento maior dos alunos com os cursos de licenciatura, possibilitando uma diminuição considerável em torno da evasão, com isso houve também a partir de alguns debates, algumas alterações nos projetos pedagógicos e um aumento considerável na utilização das tecnologias para a formação docente. A evasão dos cursos de licenciatura sempre foi uma preocupação constante do Ministério da Educação, a partir desse viés, o PIBID possui um papel fundamental na manutenção e permanência dos estudantes nos cursos de licenciatura.

Em relação as Instituições de Ensino Superior (IES) e as escolas de rede pública, o PIBID promove discussão sobre a prática docente de forma coletiva, desenvolvendo atividades interdisciplinares, recuperando a credibilidade da escola da rede pública. Essa interação entre ambas contribui de maneira significativa, pois os seus resultados são importantes para que seja possível rever e repensar como o currículo das licenciaturas.

O PIBID ainda contribui para a inserção de novas metodologias e tecnologias na formação de docentes, de maneira contextualizada e comprometida com o processo educacional, estimula à produção de materiais didáticos, incentiva a participação efetiva dos bolsistas em eventos acadêmicos e científicos a nível nacional e internacional, encorajando a formação continuada. Outro aspecto que impacta de forma positiva dentro do âmbito escolar é presença dos 
bolsistas, esses estudantes servem de inspiração para os alunos que ainda vão ingressar na faculdade e ao mesmo tempo incentiva a mudança e a inovação dentro da própria IES.

A partir dos resultados, os envolvidos nesse processo também apontam algumas sugestões de melhorias, pois algumas vezes criam alguns obstáculos relacionados às questões burocráticas é necessário realizar um aperfeiçoamento dos procedimentos burocráticos (necessidade de mais velocidade na liberação das verbas), a disposição de recursos de material didático (acervo bibliográfico e laboratórios das escolas) e o aumento de bolsas para mais de um coordenador de área, devido à demanda de bolsistas e professores supervisores.

Outro aspecto ainda levantando e que consequentemente deveria ser revisto é a correção do valor da bolsa e a concessão de auxilio transporte. O programa também se beneficiaria com um envolvimento maior com outras IES por meio de encontros periódicos a nível regional e nacional, possibilitando maior troca de experiências e interação entre os estudantes.

Segundo o relatório publicado pela Fundação Carlos Chagas, GATTI et al (2014) mostram que o PIBID enriquece a formação docente por meio das trocas, dos debates e da vivência entre Professores, Supervisores e os licenciandos Bolsistas, estimulando intervenções dentro da escola e ao mesmo tempo a construção de uma prática mais reflexiva, o que consequentemente gera a construção de novos saberes. Altera de forma eficaz a forma como os licenciandos enxergam o espaço escolar, desenvolvendo de maneira efetiva à docência, as fundamentações teóricas e a pesquisa, esses impactos refletem de maneira enriquecedora, tanto dentro da escola, como na própria IES.

Outra contribuição do programa está relacionada ao processo de aprendizagem, os licenciados contribuem de maneira significativa em relação aos alunos que apresentam dificuldades de aprendizagem, auxiliando na superação dessas dificuldades e ao mesmo tempo buscam despertar o conhecimento dos mesmos.

O Programa também traz a consciência para os bolsistas de todos os problemas que emergem da realidade em relação ao sistema educacional brasileiro presente, pois o licenciando não se torna um mero observador, mas um protagonista de sua própria prática e de sua formação, pois o mesmo tem a oportunidade de experiênciar e criar maneiras inovadoras de ensinar, refletir, debater e pesquisar, comtemplando a didática e metodologia diversificada.

O PIBID possibilita um elo entre a teoria e prática, no qual traz equilíbrio na formação docente, ao contrário do estágio no qual o conhecimento se torna mais reduzido, e as orientações em torno da prática na maioria das vezes são inexistentes, dando mais ênfase a observação do que a prática em si. O programa traz um aprendizado mais significativo, pois 
os licenciados possuem um tempo de permanência maior dentro do espaço escolar, isso faz com que o bolsista tenha uma visão mais panorâmica sobre a escola, principalmente em relação à prática, trazendo confiança e segurança para que o licenciando consiga planejar as atividades e criar materiais didáticos, sempre com a orientação e o acompanhamento do Supervisor e Coordenador de área.

O Programa é de suma importância na formação docente, pois desperta o interesse e o comprometimento do licenciado diante de sua formação, valoriza e fortalece a formação docente, traz melhoria em relação à qualidade nas escolas de rede pública, integrando as universidades e escolas, propicia a formação continuada dos professores da IES e Supervisores da escola. Além disso, o PIBID possibilita o avanço da pesquisa voltada para a educação, há melhoria na qualidade dos cursos, devido ao fato de existir uma reflexão em torno do currículo dos cursos de licenciatura, partindo de um pressuposto de articular saberes da ciência e da educação, trazendo melhorias na qualidade do ensino, estimulando e incentivando a criatividade dos bolsistas dentro do espaço escolar.

\begin{abstract}
Como tendências mais fortes da contribuição do PIBID à formação continuada dos próprios CA, os das regiões Sul-Sudeste apontam: sua atualização nos aspectos pedagógicos das disciplinas e nas tecnologias, o propiciar a aproximação dos professores das IES do contexto escolar e o estímulo à busca de soluções para o ensino e outras atividades escolares, bem como o planejamento das ações, o experimentar novas metodologias de forma, também, a preparar melhor os bolsistas, aproximando mais consistentemente a teoria da prática. Aparece com algum relevo a contribuição do trabalho com o PIBID para a modificação de posturas dos docentes do curso de licenciatura: maior interesse, participação e novas perspectivas sobre a relação teoria-práticas docentes. (GATTI et al, 2014, p. 27).
\end{abstract}

O PIBID é extremamente necessário para a busca de uma formação profissional, o programa enrique o currículo e torna a formação inicial docente mais sólida, elevando a qualidade nos cursos de formação, conforme o relato de todos os envolvidos no projeto. Metodologicamente o programa proporciona a articulação entre a teoria e a prática, trazendo consigo a oportunidade do estudante se aproximar da realidade do cotidiano escolar, e ao mesmo tempo incentiva a pesquisa, desenvolve a comunicação e a escrita dos licenciados, dando a oportunidade de levantar questionamento em relação a prática, de forma fundamentada e reflexiva.

\title{
CONSIDERAÇÔES FINAIS
}

$\mathrm{O}$ artigo buscou trazer um olhar amplo do Programa Institucional de Iniciação Docente (PIBID), por meio de uma análise panorâmica do Programa a nível Nacional. Durante este trabalho pode-se perceber que as trocas de gestão do programa dificultam o seu desenvolvimento e longevidade. Os participantes e coordenadores possuem receio quanto ao 
futuro do PIBID já que na troca de gestão pública educacional as pessoas que assumem muitas vezes descontinuam os programas em andamento, mesmo que apresentem bons resultados. Tal situação se mostra presente, visto que foi necessário criar um decreto para garantir a continuidade do programa.

Diante do panorama educacional atual, a forma como a prática está sendo conduzida dentro da formação inicial docente se torna insuficiente e fragmentada. Gatti (2010) elabora que quando a prática é contemplada dentro da grade curricular a mesma é mais voltada à observação, sendo assim a aplicação da docência fica em segundo plano. Saviani (2013) afirma que se a teoria for separada da prática ela se torna apenas uma atividade intelectual, por outro lado se separarmos a prática da teoria ela se torna meramente uma atividade de improviso. Para Pimenta (1994) é preciso que o docente possa ter noções básicas de como será o seu trabalho dentro da sala de aula e quais são os instrumentos necessários para exercer o seu papel. Isso ressalta a importância da práxis na formação docente como norteadora de uma formação qualificada.

Os estudos de Pimenta (2005) vão de encontro aos princípios do PIBID de envolver intencionalmente a formação docente de forma contextualizada, por meio da práxis docente, pois o saber não se faz apenas da prática, uma vez que a mesma precisa de fundamentação teórica para que o professor possa refletir e analisar a sua prática docente, compreendendo as mais diversas situações vivenciadas do seu cotidiano.

O PIBID tem como concepção pedagógica uma formação pautada na colaboração de uma construção de uma nova cultura educacional, com embasamento teórico e metodológico, articulando formação docente, universidade e escola, docentes e discentes, propiciando a interação entre os saberes prévios da docência, os conhecimentos teórico-práticos e saberes da pesquisa acadêmica. O programa acredita em uma ação transformadora do conhecimento da prática, o futuro professor precisa ser um sujeito ativo na sua formação para que a prática seja transformadora e possa ser modificada pela ação-reflexiva.

O Programa traz grandes contribuições, tanto dentro das Universidades, como no âmbito escolar. A participação dos bolsistas, trouxe êxito e potencializou a reabertura e melhoria na utilização dos espaços escolares, por meio das atividades mobilizadoras nesses espaços, tal como a utilização do laboratório de ciências, informática, bibliotecas, brinquedoteca, espaço esportivos e artísticos. Apesar de não ser o foco do programa, o PIBID por meio de seus resultados influenciou de maneira enriquecedora no aumento do índice do IDEB nas escolas participantes em $40 \%$ em relação aos resultados anteriores. 
A evasão dos cursos de licenciatura, sempre foi uma preocupação constante do Ministério da Educação, dentro desse contexto o PIBID possui um papel fundamental na manutenção e permanência dos estudantes nos cursos de licenciatura, pois desde a sua implementação houve uma diminuição considerável dentro desse aspecto. O programa ainda contribui para a inserção de novas metodologias e tecnologias na formação de docentes, de maneira contextualizada e comprometida com o processo educacional, estimula a produção de materiais didáticos e incentiva a participação efetiva dos bolsistas em eventos acadêmicos e científicos a nível nacional e internacional, encorajando a formação continuada.

O PIBID traz a consciência para os bolsistas dos problemas que emergem em relação ao sistema educacional brasileiro, pois o licenciando não se torna um mero observador, mas um protagonista de sua própria prática e de sua formação. É apresentada a ele a oportunidade de vivenciar e criar maneiras inovadoras de ensinar, refletir, debater e pesquisar, contemplando a didática e metodologia diversificada, pontos essenciais na formação docente. O programa traz melhoria em relação à qualidade nas escolas de rede pública, propicia também a formação continuada dos professores da IES e Supervisores da escola, por meio da integração da escola com a Instituição de Ensino Superior.

\section{REFERÊNCIAS}

BRASIL. Ministério da Educação. Coordenação de Aperfeiçoamento de Pessoal de Nível Superior. PIBID - Programa Institucional de Bolsa de Iniciação à Docência. Disponível em: 〈https://goo.gl/iSNnyr>. Acesso em: 23 set. 2016.

BRASIL. Ministério da Educação. Diretoria de Formação de Professores da Educação Básica. Relatório de Gestão 2009-2013. Disponível em: 〈https://goo.gl/vZ7k0y>. Acesso em: 05 set. 2016.

BRASIL. Ministério da Educação. Coordenação de Aperfeiçoamento de Pessoal de Nível Superior. Relatório de Gestão DEB 2009 - 2014. Disponível em: <https://goo.gl/RxLBnR>. Acesso em: 23 set. 2016.

BRASIL. Ministério da Educação. Programa de Bolsa Institucional de Iniciação à Docência - PIBID. Portaria 38/2007. Disponível em: <https://goo.gl/ComSeu>. Acesso em: 04 set. 2016

BRASIL. Ministério da Educação. Programa de Bolsa Institucional de Iniciação à Docência - PIBID. Portaria 122/2009. Disponível em: 〈https://goo.gl/usQU4j>. Acesso em: 04 set. 2016. 
BRASIL. Ministério da Educação. Regulamento do Programa Institucional de Bolsa de Iniciação à Docência (PIBID). Portaria 096/2013. Disponível em: <https://goo.gl/Xmnppw>. Acesso em: 27 ago. 2016.

GATTI, Bernadete. Formação de professores no Brasil: características e problemas.

Educação e Sociedade, Campinas, v. 31, n. 113, p. 1355-1379, out-dez 2010. Disponível em: <https://goo.gl/A3kYcH>. Acesso em: 02 jun. 2016.

GATTI, Bernadete. Formação de professores e carreira: problemas e movimentos de renovação. Campinas, SP: Autores Associados, 1997.

GATTI, Bernadete, et al. Um estudo avaliativo do Programa Institucional de Bolsa de Iniciação à Docência. FUNDAÇÃO CARLOS CHAGAS. São Paulo, 2014. Disponível em: <https://goo.gl/6gZikP>. Acesso em: 04 out. 2016.

LIBÂNEO, José Carlos. Adeus professor, adeus professora? Novas exigências educacionais e profissão docente. 10. ed. São Paulo: Cortez, 2007.

PIMENTA, Selma Garrido. O estágio na formação de professores: unidade teoria e prática. São Paulo: Cortez, 1994.

PIMENTA, Selma Garrido; LIMA, Maria Socorro Lucena. Estágio e docência. São Paulo: Cortez, 2004.

PIMENTA, Selma Garrido. (Org.). Professor reflexivo no Brasil: gênese e crítica de um conceito. 3. ed. São Paulo: Cortez, 2005.

VÁSQUEZ, Adolfo Sanchez. Filosofia da Práxis. Tradução de Luiz Fernando Cardoso. Rio de Janeiro: Paz e Terra, 1977.

SAVIANI, Dermeval. Pedagogia histórico crítica: primeiras aproximações. 11. ed. Campinas, SP: Autores Associados, 2013.

SEVERINO, Antonio Joaquim.; Docência e pesquisa: o PIBIC e o PIBID como estratégias pedagógicas. Revista Intersaberes, v. 11, n. 22 (2016). Disponível em:

<https://goo.gl/qESrex>. Acesso em: 02 jun. 2016.

SEVERINO, Antonio Joaquim. Metodologia do trabalho científico. 23. ed. São Paulo: Cortez, 2007.

TARDIF, Maurice. Saberes docentes e formação profissional. Petrópolis: Vozes, 2007 


\section{Agradecimentos}

Agradecemos ao Programa de Bolsas de iniciação á Docência - PIBID-CAPES pela possibilidade de estarmos efetivamente mais horas na escola, percebendo a práxis docente. Agradecemos a todos os pibidianos (as) que fazem este programa acontecer em todo o Brasil.

\section{${ }^{\mathrm{i}}$ Sobre as autoras}

\section{Desiré Luciane Dominschek}

E-mail: desiredominschek@ hotmail.com / ORCID: http://orcid.org/0000-0001-9678-4230

Universidade Estadual de Campinas - Brasil

Doutorado em Educação pela Universidade Estadual de Campinas (UNICAMP)

\section{Tabatha Castro Alves}

E-mail: tabatha@gmail.com / ORCID : https://orcid.org/0000-0001-7069-6398

Centro Universitário Internacional - Brasil

Especialista em Psicopedagogia - UNINTER 